\title{
MR Spektroskopi Sinyalleri Kullanılarak LSTM Derin Sinir Ağları ile Beyinde Sahte Tümörlerin Tespiti
}

\author{
Emre Dand $11^{1 *}$, Semih Karaca ${ }^{2}$ \\ ${ }^{1}$ Bilecik Şeyh Edebali Üniversitesi, Mühendislik Fakültesi, Bilgisayar Mühendisliği Bölümü, Bilecik, Türkiye (ORCID: 0000-0001-6559-1399) \\ 2 Bilecik Şeyh Edebali Üniversitesi, Lisansüstü Eğitim Enstitüsü, Bilgisayar Mühendisliği Anabilim Dalı, Bilecik, Türkiye (ORCID: 0000-0002-6214-7601)
}

(Bu yayın 26-27 Haziran 2020 tarihinde HORA-2020 kongresinde sözlü olarak sunulmuştur.)

(DOI: 10.31590/ejosat.780675)

ATIF/REFERENCE: Dandıl, E. \& Karaca, S. (2020). MR Spektroskopi Sinyalleri Kullanılarak LSTM Derin Sinir Ağları ile Beyinde Sahte Tümörlerin Tespiti. Avrupa Bilim ve Teknoloji Dergisi, (Special Issue), 426-433.

$\ddot{\mathbf{O z}}$

Manyetik rezonans spektroskopi (MRS) günümüzde beyin tümörlerinin tespitinde kullanılan müdahalesiz araçlardan biridir. Biyopsi gibi ameliyata bağlı enfeksiyon ve ölüm riski getirmediği için hekimler tarafından yaygın olarak tercih edilmektedir. MRS beyinle ilgili metabolik bir profil sunmaktadır. Tümör ve sahte tümörlerin MRS örüntüleri birbirleri ile benzerlik gösterebilmektedir. Bu sebepten dolayı beyin tümörünün doğru teşhisi ve sınıflandırılması, hastanın tedavi planlaması açısından hayati bir önem taşımaktadır. $\mathrm{Bu}$ çalışmada, MRS verileri kullanılarak, derin sinir ağları ile gerçek ve sahte beyin tümörlerinin sınıflandırılması sağlanmıştır. Çalışma kapsamında yürütülen deneysel çalışmalarda, LSTM (Long Short Term Memory - Uzun Kısa Süreli Bellek) ve Bi-LSTM (Bi-directional Long Short Term Memory - Çift Yönlü Uzun Kısa Süreli Bellek) derin sinir ağları mimarileri kullanılmıştır. Çalışmada INTERPRET veritabanında bulunan tümör ve sahte tümörlere ait MRS sinyal örüntüleri kullanılmıştır. LSTM sinir ağlarının eğitimi ve test edilmesi için çok sayıda tümör ve sahte tümöre ait MRS verisini elde etmek gerçek dünyada zor bir prosedürel süreç olduğundan, ağ eğitilmeden ve test edilmeden önce, MRS veriseti için veri büyütme (çoğaltma) yöntemleri ile veri sayısı çoğaltılmıştır. LSTM sinir ağları, hem veri çoğaltma olmadan hem de veri çoğaltma ile eğitilmiş ve test edilmiştir. Kullanılan LSTM sinir ağlarının eğitim ve testleri esnasında her model için tekrarlı K-kat çapraz doğrulama yöntemi kullanılmıştır. Eğitimler, her model için 5 kat ve 10 tekrar ile yapılmıştır. MRS verilerini bilgisayar destekli sınıflandırmaya dayalı bir yöntem ile sınıflandıran bu çalışma sonucunda, geliştirilen uygulama ile veri çoğaltma olmadan yapılan testlerde, kullanılan iki mimari için ortalama \%81.15 doğruluk başarımı elde edilirken; veri çoğaltma yapıldıktan sonra yapılan testlerde, her iki mimari için ortalama \%95.15 doğruluk başarımı elde edilmiştir.

Anahtar Kelimeler: Beyin tümörleri, MRS, Sınıflandırma, Derin Öğrenme, LSTM, Bi-LSTM

\section{Detection of Pseudo Brain Tumors via LSTM Neural Networks using MR Spectroscopy Signals}

\begin{abstract}
Magnetic resonance spectroscopy (MRS) is one of the non-invasive tools used in the detection of brain tumors today. It is widely preferred by physicians because it does not pose a risk of surgical infection and death such as biopsy. MRS provides a metabolic profile about the brain. MRS patterns of tumors and pseudo tumors can be similar to each other. For this reason, accurate diagnosis and classification of the brain tumor is vital for the treatment of the patient. In this study, the classification of real and pseudo brain tumors with deep neural networks was provided by using MRS data. In experimental studies carried out within the scope of the study, LSTM (Long Short Term Memory) and Bi-LSTM (Bidirectional Long Short Term Memory) deep neural network architectures were
\end{abstract}

* Sorumlu Yazar: Bilecik Şeyh Edebali Üniversitesi, Mühendislik Fakültesi, Bilgisayar Mühendisliği Bölümü, Bilecik, Türkiye (ORCID: 0000-00016559-1399, emre.dandil@bilecik.edu.tr 
used. In the study, MRS signal patterns of tumors and pseudo tumors in the INTERPRET database were used. Since obtaining MRS data from a large number of tumors and pseudo tumors for the training and testing of LSTM neural networks is a difficult procedural process in the real world, the number of data has been increased by MRS data augmentation (replication) methods before the network is trained and tested. LSTM neural networks are trained and tested both with and without data augmentation methods. During the training and testing of the LSTM neural networks, repeated K-fold cross-validation method was used for each model. Neural network trainings were carried out with 5 folds and 10 repetitions for each model. As a result of this study which classifies MRS data with a method based on computer-aided classification; in the tests carried out without data augmentation with the developed application, an average of $81.15 \%$ accuracy was achieved for the 2 neural network architectures while in the tests performed after data augmentation, an average of $95.15 \%$ accuracy performance was achieved for both networks.

\section{Keywords: Brain Tumors, MRS, Classification, Deep Learning, LSTM, Bi-LSTM}

\section{Giriş}

Günümüzde, insan ölümlerinin başlica sebeplerinden ikincisi kanserdir (Fitzmaurice vd., 2017). Dünya sağlık örgütüne göre kanser, 2018 yılında 9.1 milyon insanın ölümüne sebep olmuştur (WHO, 2018). Beyin tümörleri, tüm kanser tipleri arasında \%2'lik bir yer kaplamasına rağmen, kanser sebepli ölüm oranlarını fazlaca arttıran bir kanser türüdür (Neugut vd., 2019). Dünya sağlık örgütünün 2020 yılında yayınladığı Dünya Kanser Raporu'na göre 2018 yılında, beyin ve merkezi sinir sistemi kanserleri en çok görülen 17. kanser tipi olurken, dünya genelinde yaklaşık olarak 297 bin yeni vaka kaydedilmiştir.

Beyin tümörlerinin teşhisinde klinik bulgular, radyolojik görüntüleme ve histopatoloji raporları önemli rol oynar. Beyin hakkında anatomik bilgi veren manyetik rezonans görüntüleme (MRG) ve beyindeki metabolitler hakkında bilgi veren manyetik rezonans spektroskopi (MRS), beyin tümörlerinin teşhisinde kullanılan müdahalesiz yöntemlerdir. Tümörlü dokunun histopatoloji raporu, tümörün doğru teşhisinde açısından en iyi yöntemdir. Ancak biyopsi, her tür tümör için uygulanamayacağı gibi beraberinde ölüm riskini de getirir (Devos vd., 2004).MRG, 1980'lerin başından beri klinik ortamda beyin tümörünün teşhisinde kullanılmaktadır (Ladd vd., 2018). Görüntüleme yöntemleri arasında en iyi yumuşak doku kontrastını veren yöntemdir (Soares \& Law, 2009). Ancak MRG düşük hassasiyete sahiptir ve tümörün tipi ve evresinin belirlenmesi konularında yanıltıcı olabilir (Hekmatnia vd., 2019). MRS, beyin tümörlerinin teşhisinde kullanılan müdahalesiz bir yöntemdir. İncelenen bölgedeki dokuda bulunan metabolitler hakkında bilgi verir. Tümörün derecesi, tipi, agresifliğinin tespiti ile iyi huylu veya kötü huylu olduğunun teşhisinde kullanılır (Majós vd., 2003). Görüntüleri birbirine benzeyen bazı tümör tiplerinin ayırt edilmesi MRG ile mümkün olmazken MRS ile teşhis konulabilmektedir.

Gliomlar, merkezi sinir sistemi tümörleridir. Histopatolojik özelliklerine göre dünya sağllk örgütü tarafından I'den IV'e dört farklı evreye ayrılmıştır (Louis vd., 2016). Evre I olarak kategorilendirilen tümörler genellikle ameliyatsız tedavi edilirler ve iyi huylu sayılırlar. Evre II beyin tümörleri genellikle iyi huylu olmasına karşın, bazı vakalarda kötü huylu da olabilmektedir. Evre III tümörler ise çoğunlukla kötü huyludur. Evre IV tümörler ise gliblastom multiform olarak adlandırılır ve en kötü huylu olanlardır. MR görüntüleri veya MRS verilerinde görülen bazı metabolit pikleri tümörler ile benzerlik gösteren fakat neoplastik olmayan yapılara sahte tümör denir. Bir lezyonun sahte tümör olarak sınıflandırılması olası bir biyopsiyi engeller ve tedavi yönetimini değiştirir. Sahte tümörlere örnek olarak; enfeksiyöz, iskemik veya demiyelinizan lezyonlar verilebilir (Horská \& Barker, 2010).

Literatürde MRS verileti kullanılarak beyin tümörlerinin tespiti, sınıflandırılması ve evrelenmesi konularından birçok çalışma bulunmaktadır. McBride ve arkadaşları (McBride vd., 1995), MRS spektrumundaki metabolitleri birbirine oranlayarak ve bunları normal beyin dokusu ile karşılaştırarak tümör tespiti yapmışlardır. Bir başka çalışmada, Butzen ve arkadaşları (Butzen vd., 2000), tümör ve sahte tümörlerin MR spektroskopisi kullanılarak sınıflandırılması için lojistik regresyon (LR) örüntü tanıma modeli önermişlerdir. Bu konudaki bir diğer çalışmada, Devos ve arkadaşları (Devos vd., 2004) beyin tümörlerine ait MRS verilerini, doğrusal diskriminant analizi ve en küçük kareler destek vektör makineleri (LS-SVMs) kullanarak sınıflandırmışlardır. Tate ve arkadaşları (Tate vd., 2006) çalışmalarında, beyin tümörlerinin tespiti ve evrelendirilmesi için bir karar destek sistemi önermişlerdir. Arús ve arkadaşları (Arús vd., 2006), beyin tümörü tespitini yapabilmek için, dağıtık servislerle çalışan web tabanlı bir karar destek sistemi önermişlerdir. Hourani ve arkadaşları (Hourani vd., 2008), MRS verilerinden elde ettikleri metabolit oran ve yoğunluklarını, diskriminant fonksiyon analizi kullanarak, tümör ve sahte tümörlerin sınıflandırılmasını önermişlerdir. Majos ve arkadaşları (Majos vd., 2009) çalışmalarında, beyindeki tümör ve sahte tümörlerin ayırt edilebilmesi için MRS verisindeki metabolitlerin birbiriyle oranlanmasına dayanan bir yöntem önermişlerdir. Weis ve arkadaşları (Weis, Ring, Olofsson, Ortiz-Nieto, \& Wikström, 2010) çalışmalarında, MRS verileri kullanılarak beyin tümörlerinin sınıflandırılmasında, fark spektrumu (DS) kullanımının avantajlı olacağını öne sürmüşlerdir. Georgadis ve arkadaşları (Georgiadis vd., 2011) çalışmalarında, beyin tümörlerini sınıflandırmak için MR görüntü özelliklerini ve MRS metabolit oranlarını birleştirerek bir örüntü tanıma yöntemi önermişlerdir. Faria ve arkadaşları (Faria, Macedo Jr, Marsaioli, Ferreira, \& Cendes, 2011) çalışmalarında, beyin tümörlerine ait MRS verilerini, örüntü tanıma metodu olarak kısmı en az kareler diskriminant analizini (PLS-DA) kullanarak sınıflandırmışlardır. Tsolaki ve arkadaşları (Tsolaki vd., 2013) çalı̧̧malarında, beyin tümörlerinin doğru bir şekilde sınıflandırılabilmesi için MRS verilerini örüntü tanıma sistemi ile işlemişledir. Vicente ve arkadaşları (Vicente vd., 2013) beyin tümörlerin sınıflandırılması için pik integrasyon yöntemi ile özellik çıkarımı ve lineer diskriminant analizi ile teşhis sınıflandırıcılarını ürettikleri bir yöntem önermişlerdir. Nachimuthu ve Baladhandapani (Nachimuthu \& Baladhandapani, 2014) çalı̧̧malarında, beyin tümörlerinin teşhisi için MR görüntülerini ve MRS verilerini kullanarak otomatikleştirilmiş bir örüntü tanıma yöntemi önermişlerdir. Arizmendi ve arkadaşları (Arizmendi, Sierra, Vellido, \& Romero, 2014) gauss ayrışması, kayan pencere ve varyans analizleri ile boyutluluk azaltma ve sınıflandırma yöntemlerini birleştirdikleri regüle bir 
derin sinir ağı ile beyin tümörlerini sınıflandırmışlardır. Vieira ve arkadaşları (Vieira, Santos, \& Salmon, 2017) MRS verileri üzerinde örüntü tanıma yöntemleri ile bir sınıflandırma metodu önermişlerdir. Crain ve arkadaşları (Crain vd., 2017) metabolitlerin pik yüksekliklerini oranlayarak bir sınıflandırma yönetimi önermişlerdir.

Tümör gibi davranan ve görüntüsel örüntüsü gerçek tümörle çok fazla eşleşen sahte tümörlerin tespiti, hasta için hayati öneme sahiptir ve tedavi planlanmasının doğru yürütülebilmesi için çok önemlidir. MRS sinyalleri yardımıyla beyin tümörlerinin tespiti için literatürde önerilen çalışmalar incelendiğinde, sahte beyin tümörlerinin gerçek tümörlerden ayrımının yapılmasında sınırlı sayıda çalışma olduğu görülmektedir. Sahte tümörlerin tespiti için önerilen sınırlı sayıdaki çalışmanın ise genellikle metabolitlerin orantısal değerlerinin yorumlamasına dayalıdır. Bu konuda önerilen karar destek sistemi, öğrenmeye dayalı bir hibrit sistem veya sınıflandırmaya dayalı bir yaklaşımın olmadığı dikkat çekmektedir. MRS verileri ile tümörlerin sınıflandırması yüksek tecrübe isteyen bir iştir. Bu çalışmada, bu işi yapan radyologların işlerini kolaylaştırmak ve karar verme aşamasında onlara bir ön fikir sunmak için bir yaklaşım sunulmuştur. Çalışmada, Evre IV gliblastom multiform beyin tümörleri ile sahte beyin tümörlerinin bilgisayar destekli sınıflandırılması için LSTM derin sinir ağlarına dayalı bir yöntem önerilmiştir. Çalışmada yürütülen deneysel çalışmalar sonucunda Bi-LSTM derin sinir ağları ile yüksek doğruluk başarımı sağlanmıştır. Çalışmanın bundan sonraki kısımları şu şekilde organize edilmiştir. İkinci bölümde, çalışmada kullanılan veriler ve derin sinir ağları anlatılmıştır. Üçüncü bölümde, verilerin işlenme yöntemi, veri çoğaltma yönetimi, ă̆ detayları ve başarımlar sunulmuştur. Son bölüm olan dördüncü bölümde ise elde edilen sonuçlar yorumlanmıştır.

\section{Materyal ve Metot}

Çalışmada önerilen sistemde başlangıç olarak, hastanın görüntülenmek istenen beyin bölgesi MR makinesi ile tarandıktan sonra MR görüntüsü ve MR spektroskopisi elde edilir. Daha sonra, MR spektroskopi verileri bu çalışmada tasarlanan derin sinir ağlarında kullanılmak üzere önce standart hale getirilir ve veri çoğaltma işlemleri yapılır. En son aşamada ise tasarlanan LSTM ağı ile sınıflandırma işlemi yapılarak tümör ve sahte tümörlerin ayrımı gerçekleştirilir.

\subsection{Manyetik Rezonans Spektroskopi ( ${ }^{1} \mathrm{H}$ MRS)}

MRS'in çalışma yapısında canlı doku üzerine güçlü manyetik alanların uygulanması vardır. Uygulanan bu dış manyetik alan ile canlı dokuda çokça bulunan hidrojen $\left({ }^{1} \mathrm{H}\right)$, fosfor $\left({ }^{31} \mathrm{P}\right)$ veya karbon $\left({ }^{13} \mathrm{C}\right)$ arasında enerji değişimi oluşturmak amaçlanır. Klinik uygulamalarda en yaygın kullanılan yöntem ${ }^{1} \mathrm{H}$ MRS'dir (Callot vd., 2008). Sonuç olarak MRS'de, beyindeki farklı metabolitlerin farklı frekans veya frekans aralıklarında pik yaptığ 1 frekans tanım kümesinde bir sinyal elde edilir. Dikey eksen sinyalin yoğunluğunu temsil ederken sinyalin yatay eksendeki frekans skalasında yeri ise milyondaki parça sayısı (parts per million, ppm) cinsinden ifade edilir. Beyinde yoğunluğu fazla olan metabolitlerin pikleri büyük olurken az olanlarınki küçük olur. Elde edilen sinyal, beyindeki doku metabolizması hakkında ölçülebilir bir profil sağlar ve tümörün teşhis ve derecelendirilmesini kolaylaştırır. Beyin tümörlerinin teşhisinde, klinik kontrollerden sonra biyopsi yapılmadan tanı konulabilmesi MRS ile mümkün olabilmektedir. MRS ile beyin gibi hassas bir organ, cerrahi operasyonların getirdiği risklerden uzak tutulmuş olur.

Beyin dokusunda, MR spektroskopisi ile görülebilecek başlıca metabolitler pikleri 3.2 ppm'de kolin (Cho), 3.0 ppm'de kreatin (Cr), 2.0 ppm'de N-asetil-aspartat (NAA), 1.3 ppm'de laktat (Lac) ve 0.9 ile 1.3 ppm'de lipid (Lip) olarak sıralanabilir (Kimura, Sako, Gotoh, Tanaka, \& Tanaka, 2001). Beyinde Cho seviyesinin yükselişi, hızlanan membran üretimi ve çoğalan beyin tümörüne işarettir (Ramin, Tognola, \& Spotti, 2003). NAA sadece nöronlarda bulunduğundan ve çoğu beyin tümörü de nöron kökenli olmadığı için tümörlü dokuda varlığı yok denecek kadar azdır (Howe \& Opstad, 2003). NAA/Cho, Cho/Cr gibi farklı metobolit yoğunluklarının birbirleri ile oranlanması ile tümörün tipi hakkında bir ön fikir elde edilebilir (Nagori \& Joshi, 2013). Şekil 1'de sağlıklı bir bireyin beyin dokusundan elde edilmiş MR spektroskopisi üzerinde bazı metabolit pikleri görülmektedir.

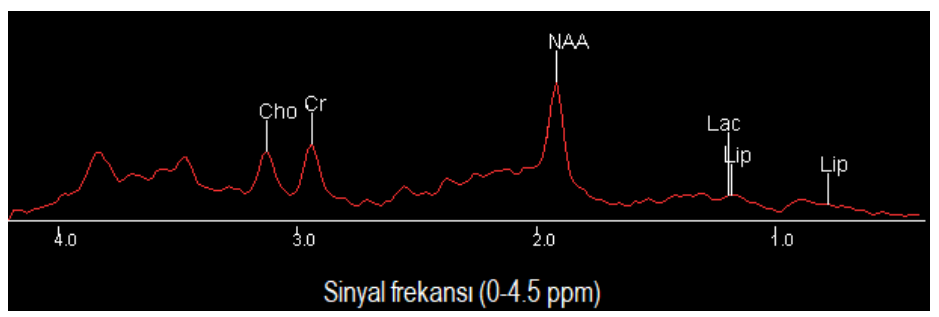

Şekil 1. Să̆lıklı beyin dokusunun MR spektrumu

\subsection{MRS Veriseti}

Çalışmada beyin sahte beyin tümörlerini tespiti için kullanılan MRS verileri INTERPRET (International Network for Pattern Recognition of Tumours using Magnetic Resonance) (INTERPRET, 2002) veritabanından alınmıştır. INTERPRET veriseti 01.01.2000-31.12.2002 tarihleri arasında çalışılmış bir AB projesidir. INTERPRET projesin amaçları arasında; MRS kullanımını yaygınlaştırmak, radyologların beyin tümörlerinin MRS kullanarak sınıflandırmasına olanak sağlamak, tedavi ve terapi süreçlerinin planlanmasına yardımcı olmak ve MRS'i biyopsi alternatifi olarak konumlandırmak sayılabilir. Bu hedefler çerçevesinde beyin tümörleri, diğer patolojik beyin kitleleri ve normal beyin dokularından oluşan yaklaşık 800 vakanın bulunduğu bir MRS veri tabanı 
oluşturulmuş̧ur. Ayrıca radyologların spektroskopi verisini daha iyi yorumlayabilmesi için bir karar destek sistemi (decision support system, DSS) yazılımı geliştirilmiştir. Bu çalışmada, INTERPRET veri tabanından alınan 29 adet IV. evredeki beyin tümörü (GBM) ve 9 adet sahte beyin tümörünün MRS verileri ile bir veri seti oluşturulmuştur. Sahte beyin tümörlerinden altısının apse olduğu bilinmektedir.

Veri setinde bulunan glioblastom ve sahte tümörlere örnek vermek için MR görüntüleri ve MR spektroskopileri Şekil 4 ve Şekil 5 'te sırasıyla gösterilmiştir. Şekil 2 ve Şekil 3'ten de görüleceği gibi glioblastom ve sahte tümör MR spektroskopisi üzerinde birbirleriyle benzerlik gösterebilmektedir. İki tümör için de $3.2 \mathrm{ppm}$ noktasında Cho piki, $2.0 \mathrm{ppm}$ noktasında NAA piki görülmektedir. Beyinde yükselen Cho miktarı genellikle hücresel yıkımı ve tümör varlığını gösterir. NAA seviyesinin düşük olması da tümörün varlığına işarettir.

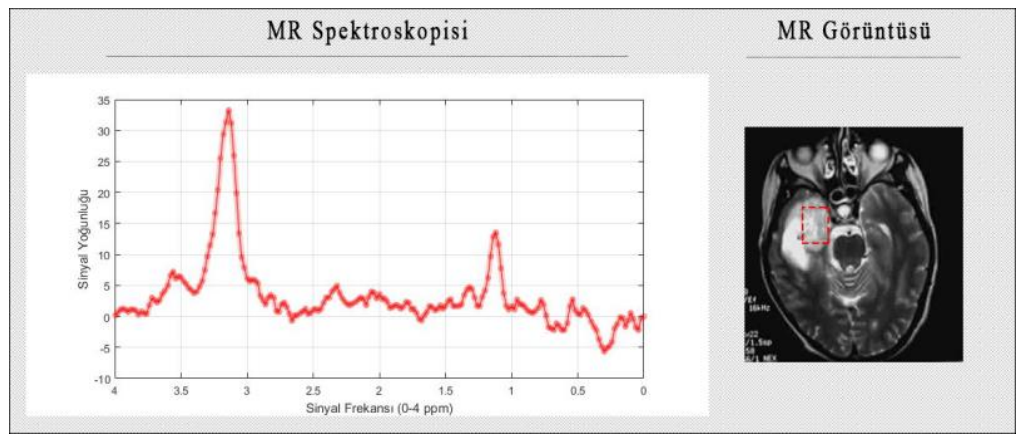

Şekil 2. Glioblastom'a ait MR spektroskopisi ve MR görüntüsü

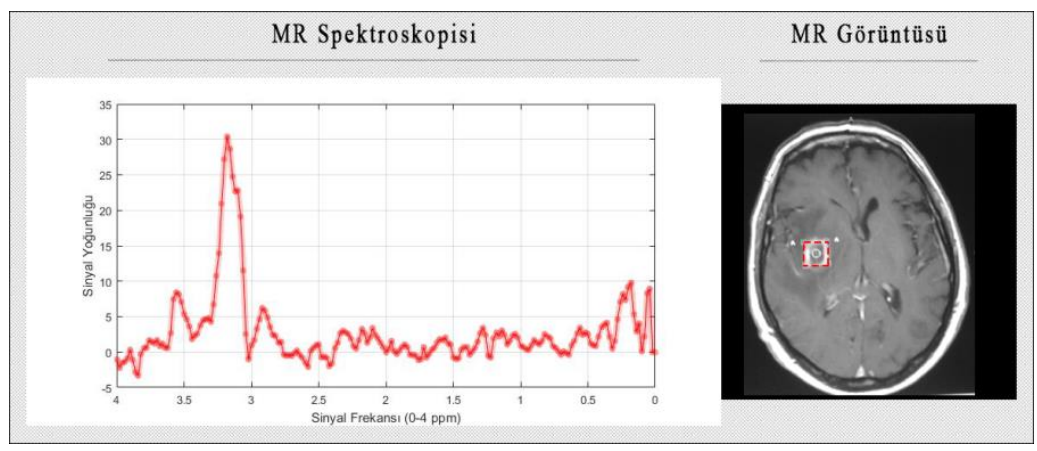

Şekil 3. Sahte tümöre ait MR spektroskopisi ve MR görüntüsü

\subsection{LSTM ve Bi-LSTM Derin Sinir Ağları}

Tekrarlayan sinir ağları (Recurrent Neural Networks, RNN); zaman serilerinin analizinde yaygın olarak kullanılan derin öğrenme algoritmalarıdır. Doğal dil işleme (Wu vd., 2016), ses tanıma (Graves, Mohamed, \& Hinton, 2013), el yazısı tanıma (Zhang, Xie, Liu, \& Bengio, 2016) gibi uygulamaların gerçeklenmesinde de kullanılırlar. Tekrarlayan sinir ağlarında diğer ileri beslemeli ağlarından farklı olarak ağın girdileri, sadece eldeki mevcut örnek değil, ağın daha önce gördüğü örnekle ilgili öğrendiklerini de içerir. Yani ağın $t-1$ zamanınında verdiği karar $t$ zamanında vereceği kararı etkilemektedir. Tekrarlayan sinir ağları ilk olarak Hopfield Ağlarında (Hopfield, 1982) tarif edilmiştir.

Hochreiter ve Schmidhuber (Hochreiter \& Schmidhuber, 1997), tekrarlayan sinir ağlarının geliştirilmiş bir versiyonu olan Uzun Kısa Süreli Bellek Ağlarını (Long Short Term Memory, LSTM) tasarlamış, kaybolan ve patlayan gradyan problemini çözmek için Şekil 4'te gösterilen hafiza bloğu kavramını geliştirmişlerdir. Hafiza bloğu sayesinde LSTM hücreleri, bilgiyi önemine göre hatırlar veya unuturlar. Önemi yüksek olan bilgi geri yayılımda kullanılırken önemi düşük olanlar unutulur. Çift Yönlü Uzun Kısa Süreli Bellek (Bi-drectional Long Short Term Memory, Bi-LSTM) ağları ise, aynı anda iki LSTM ağının eğitilmesi ile mantığı ile çalışır (Schuster \& Paliwal, 1997). Ağın girdisi, olduğu gibi ve zamana göre ters çevrilmiş hali ile kullanılır. Böylece ağ, geçmiş hakkındaki bilgilerin yanı sıra gelecek hakkında bilgileri de tutar. Hafiza bloğu kapılardan oluşur ve bunlar; unutma kapısı, giriş kapısı, güncelleme kapısı ve çıkış kapılarıdır. LSTM modeli için eşitlikler aşağıdaki gibi gösterilebilir:

$$
\begin{aligned}
& f_{t}=\sigma\left(w_{f} \cdot\left[h_{t-1}, x_{t}\right]+b_{f}\right) \\
& i_{t}=\sigma\left(w_{i} \cdot\left[h_{t-1}, x_{t}\right]+b_{i}\right) \\
& g_{t}=\tanh \left(w_{g} \cdot\left[h_{t-1}, x_{t}\right]+b_{g}\right) \\
& c_{t}=f_{t} * c_{t-1}+i_{t} * g_{t} \\
& o_{t}=\sigma\left(w_{o} \cdot\left[h_{t-1}, x_{t}\right]+b_{o}\right) \\
& h_{t}=o_{t} * \tanh \left(c_{t}\right)
\end{aligned}
$$


Unutma kapısının çıktısı $f_{t}$, eşitlik (1)'de, giriş kapısının çıktısı $i_{t}$, eşitlik (2)'de, güncelleme kapısının çıktısı $g_{t}$ eşitlik (3)'te ve çıkış kapısının çıktısı $o_{t}$ eşitlik (5)'te verilmiştir. Bu dört kapının girdisi olarak bir önceki zaman adımı olan $t-1$ adımının gizlilik durumu $h_{t-1}$ ve şimdiki zamanın girdisi $x_{t}$ kullanılır. $w_{f, i, g, o}$ ağırlık matrisleri iken, $b_{f, i, g, o}$ bayas vektörüdür. Hafıza hücresi $c_{t}$ eşitlik (4)'te sunulmuştur. Eşitlik (6)'da hücrenin gizlilik durumu $h_{t}$ 'nin hesabı vardır. sigmoid aktivasyonu fonksiyonu $\sigma$ olarak gösterilmiştir. Matris çarpımı "“" ve eleman elemana matris çarpımı "*” ile gösterilmiştir.

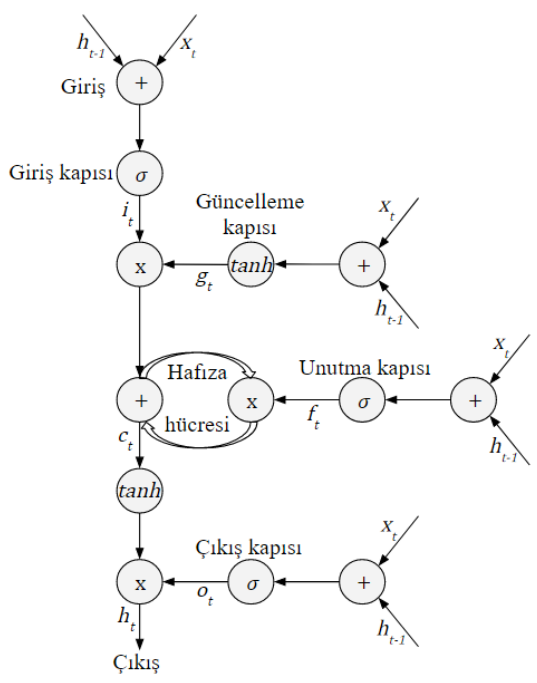

Şekil 4. LSTM derin sinir ağlarında hafiza hücresi yapısı

\section{Araştırma Sonuçları ve Tartışma}

Bu çalışmada, INTERPRET veri tabanından alınan 29 adet IV. Evre glioblastom tümör (GBM) ve 9 adet sahte tümöre ait MR spektroskopi verilerin LSTM ve Bi-LSTM derin sinir ağları ile sınıflandırıldığı bir model oluşturulmuştur. Her iki sınıfın da başlangıçta aynı sayıda örneğe sahip olması için sahte tümör verileri kopyalanarak sayıları 29'a çıkarılmıştır ve toplamda 58 veri noktası ile çalışılmıştır. Her bir hastanın MR verisi, 200 veri noktası ve bir etiketten oluşan vektörlere çevrilmiştir. Sonuç olarak $58 \times 201$ boyutunda bir matris oluşturulmuştur.

$\mathrm{Bu}$ çalışma, Intel i7-4790k işlemci, 8GB bellek ve NVDIA Geforce GTX 970 ekran kartına sahip Windows 10 işletim sistemiyle çalışan bir bilgisayarda yapılmıştır. Uygulama Python programlama dili ile geliştirilmiştir. Tensorflow makine öğrenme kütüphanesi, kullanımı kolaylaştırmak için yüksek seviye sinir ağı API'si olan Keras ile kullanılmıştır. Tensorflow için GPU desteği CUDA Toolkit ve CuDNN SDK ile sağlanmıştır. Pandas, numpy, sklearn, matplotlib gibi makine öğrenme problemlerinde sıkça kullanılan kütüphaneler kullanılmıştır.

Veri içe aktarıldıktan sonra kendi içinde rasgele bir şekilde karıştırılmıştır. Bu rastgeleliğin ve uygulamanın diğer yerlerinde yapılan rasgele işlemlerin tekrarlanabilir olması için bir rastgelelik tohumu (seed) kullanılmıştır. Veriler 58x200 boyutlu, etiketleri ise 58x1 boyutlu bir matrise alındıktan sonra veriler üzerinde normalizasyon işlemi uygulanmıştır. Bu işlemden sonra tekrarlı katlı çapraz doğrulama işlemi yapılmıştır. Bu çalışmada 5 katlı çapraz doğrulama yapılmış ve eğitim ve test verilerinin her doğrulama iterasyonu için uygulanmıştır. Bu çalışmada kullanılan veri setindeki GBM ve sahte tümörler örneklerinin sayılarının az olması sebebiyle derin sinir ağları, hem eldeki verilerle hem de veri çoğaltma işlemi yapılarak eğitilmiş ve test edilmiştir. Veri çoğaltma işlemlerinden sonra derin LSTM sinir ağı oluşturulmuş ve bölünen örnekler ile eğitim ve testler yapılmıştır. Model, her bir çapraz doğrulama için 25 epok ile eğitilmiş ve test verileri ile model başarımı hesaplanmıştır. Genel başarım ise 50 çapraz doğrulamanın başarımlarının ortalaması şeklinde alınmıştır. Tablo 1'de, gerçeklenen LSTM modeli için her bir katmandaki girdi ve çıktı boyutları ile eğitilebilir parametre sayıları verilirken Tablo 2'de bu bilgiler Bi-LSTM modeli için verilmiştir. Örnek sayısı değişkenlik gösterdiği için “\#” ile belirtilmiştir.

Tablo 1. LSTM modeli için detaylar

\begin{tabular}{|c|l|l|l|l|}
\hline \multirow{4}{*}{$\downarrow$} & Katman & Girdi Boyutu & Çıktı Boyutu & Eğitilebilir Parametreler \\
\cline { 2 - 5 } & Giriş & - & $(\#, 1,200)$ & - \\
\cline { 2 - 5 } & LSTM(200) & $(\#, 1,200)$ & $(\#, 1,200)$ & 320800 \\
\cline { 2 - 5 } & Flatten & $(\#, 1,200)$ & $(\#, 200)$ & - \\
\cline { 2 - 5 } & Dense & $(\#, 200)$ & $(\#, 1)$ & 201 \\
\hline \multicolumn{2}{|r}{ Toplam } & - & - & 321001 \\
\hline
\end{tabular}


Tablo 2. Bi-LSTM modeli için detaylar

\begin{tabular}{|c|l|l|l|l|}
\hline \multirow{4}{*}{$\downarrow$} & \multicolumn{1}{|c|}{ Katman } & Girdi Boyutu & Çıktı Boyutu & \multicolumn{1}{c|}{ Eğitilebilir Parametreler } \\
\cline { 2 - 5 } & Giriş & - & $(\#, 1,200)$ & - \\
\cline { 2 - 5 } & Bi-LSTM(200) & $(\#, 1,200)$ & $(\#, 1,400)$ & 641600 \\
\cline { 2 - 5 } & Flatten & $(\#, 1,200)$ & $(\#, 200)$ & - \\
\cline { 2 - 5 } & Dense & $(\#, 200)$ & $(\#, 1)$ & 401 \\
\hline \multicolumn{2}{r}{ Toplam } & - & - & 642001 \\
\hline
\end{tabular}

Toplamda 50 defa tekrarlanan eğitimlerin ve testlerin sonrasında, veri çoğaltma olmadan elde edilen doğrulukların ortalaması ve standart sapmaları, testlerin tümü için hassaslık ve özgünlük değerleri Tablo 3'te, veri çoğaltma ile elde edilenler ise Tablo 4'te verilmiştir. Doğruluk, hassaslık ve özgünlük hesaplamaları için GBM tümör negatif (0), sahte tümör ise pozitif (1) olarak alınmıştır. Bu değerlerin hesaplanması Gerçek Pozitif (GP), Gerçek Negatif (GN), Yanlış Pozitif (YP) ve Yanlış Negatif (YN) sayıları ile yapıılır. GP; gerçekte sahte tümör olup sahte tümör olarak sınıflandırılanları, GN; gerçekte GBM tümör olup GBM tümör olarak sınıflandırılanları, YP; gerçekte sahte tümör olup GBM tümör olarak sınıflandırılanları, YN; gerçekte GBM tümör olup sahte tümör olarak sınıflandırılanları göstermektedir. Doğruluk, hassaslık ve özgünlük için kullanılan eşitlikler, eşitlik 10,11 ve 12'de sunulmuştur.

$$
\begin{aligned}
& \text { Doğruluk }=\frac{\mathrm{GP}+\mathrm{GN}}{\mathrm{GP}+\mathrm{GN}+\mathrm{YP}+\mathrm{YN}} \\
& \text { Hassaslık }=\frac{\mathrm{GP}}{\mathrm{GP}+\mathrm{YN}} \\
& \text { Özgünlük }=\frac{\mathrm{GN}}{\mathrm{GN}+\mathrm{YP}}
\end{aligned}
$$

Tablo 3. Veri çoğaltma olmadan doğruluk, hassaslık ve özgünlük değerleri

\begin{tabular}{|l|l|l|l|l|l|}
\hline Model & Ĕ̆gitim örnek sayısı & Test örnek sayısı & Doğruluk & Hassaslık & Özgünlük \\
\hline LSTM & $\sim 46$ & $\sim 12$ & $81.18 \%(+/-9.09 \%)$ & $65.52 \%$ & $96.90 \%$ \\
\hline Bi-LSTM & $\sim 46$ & $\sim 12$ & $81.12 \%(+/-9.49 \%)$ & $67.59 \%$ & $94.83 \%$ \\
\hline
\end{tabular}

Tablo 4. Veri çoğaltma ile doğruluk, hassaslık ve özgünlük dĕgerleri

\begin{tabular}{|l|l|l|l|l|l|}
\hline Model & Ĕğitim örnek sayısı & Test örnek sayısı & Doğruluk & Hassaslık & Özgünlük \\
\hline LSTM & $\sim 690$ & $\sim 180$ & $95.12 \%(+/-5.58 \%)$ & $100.00 \%$ & $90.23 \%$ \\
\hline Bi-LSTM & $\sim 690$ & $\sim 180$ & $95.17 \%(+/-5.04 \%)$ & $100.00 \%$ & $90.32 \%$ \\
\hline
\end{tabular}

LSTM ile Bi-LSTM modellerinin birbirlerine çok yakın başarımlar elde ettiği görülürken, çalışmada kullanılan veri çoğaltma yönteminin başarımı arttırma konusunda etkili olduğu görülmüştür. Çalışmada kullanılan derin sinir ağı modelleri, LSTM ve BiLSTM katmanlarının kendi içinde veya birbirleriyle katmanlı bir yapıda bağlanarak oluşturulan deneysel yapılar ile test edilmiş fakat başarımda bir artık gözlenememiştir. Yine bu modeller için LSTM ve Bi-LSTM katmanlarının önüne veya sonuna bağlanan klasik sinir ağı yapıları da başarımda bir artık sağlamamıştır. Model sade haliyle verebileceği en iyi yüksek başarımı elde etmiştir.

\section{Sonuç}

Bu çalışmada, hem tek yönlü ve hem de çift yönlü uzun kısa zaman hafizalı derin sinir ağları kullanılarak beyin tümörlerinin bilgisayar destekli sınıflandırılması sağlanmıştır. Her iki yöntem için de sırasıyla $95.12 \%$ ve $95.17 \%$ ortalama başarım elde edilmiştir. Bi-LSTM modeli için eğitilebilir parametre sayısı LSTM ağının iki katı olmasına rağmen başarımlar arasındaki fark sadece $0.05 \%$ olarak kalmıştır. Bi-LSTM modelinde MRS sinyalinin tersinin ağın eğitiminde kullanılması ve ağın gelecek ile ilgili tuttuğu bilgiler öğrenmeye fazla etki etmemiştir. Eldeki veriler farklı kombinasyonlar ile defalarca eğitim ve test için bölündüğünden elde edilen sonuçlar sadece bir kümenin değil birçok kümenin başarımını, yani uygulanan modellerin başarımını göstermektedir. Çalışmamızda sınıflandırmaya çalıştığımız 2 tümör tipi için elimizde bir sınıftan sadece 9 örnek olmasından dolayı veri çoğaltma yöntemi kullanılmıştır. Veri çoğaltma işlemi mevcut verilerin kopyalanması ile de yapılabileceği gibi eşsiz ve farklı veriler elde etmek adına veriyi çok farklılaştırmadan rastgelelik katılarak çoğaltılmıştır. Gelecek çalışmalarda, MRS verilerinin çoğaltılması için farklı yöntemler tek başına veya birlikte kullanılarak yapay veriler elde edilebilir. Kullanılan ağın parametrelerinde ince ayar yapılarak sonuçlar değerlendirebilir. Tümör sınıflandırılması için evrişimsel derin sinir ağları ile LSTM ağlarının birleşimi ile oluşturulacak bir model daha iyi sonuçlar verebilir.

\section{Teşekkür}

Bu çalışmada, sınıflandırılan MRS verilerinin yer aldığı INTERPRET veri tabanının oluşturulmasında emeği geçen tüm bilim adamlarına ve projeyi finanse eden Avrupa komisyonuna teşekkürlerimizi sunarız. 


\section{Kaynakça}

Arizmendi, C., Sierra, D. A., Vellido, A., \& Romero, E. (2014). Automated classification of brain tumours from short echo time in vivo MRS data using Gaussian Decomposition and Bayesian Neural Networks. Expert systems with applications, 41(11), 5296-5307.

Arús, C., Celda, B., Dasmahaptra, S., Dupplaw, D., Gonzalez-Velez, H., Van Huffel, S., . . Peet, A. (2006). On the design of a webbased decision support system for brain tumour diagnosis using distributed agents. Paper presented at the 2006 IEEE/WIC/ACM International Conference on Web Intelligence and Intelligent Agent Technology Workshops.

Butzen, J., Prost, R., Chetty, V., Donahue, K., Neppl, R., Bowen, W., . . . Kim, T. (2000). Discrimination between neoplastic and nonneoplastic brain lesions by use of proton MR spectroscopy: the limits of accuracy with a logistic regression model. American journal of neuroradiology, 21(7), 1213-1219.

Callot, V., Galanaud, D., Le Fur, Y., Confort-Gouny, S., Ranjeva, J.-P., \& Cozzone, P. J. (2008). 1H MR spectroscopy of human brain tumours: a practical approach. European journal of radiology, 67(2), 268-274.

Crain, I. D., Elias, P. S., Chapple, K., Scheck, A. C., Karis, J. P., \& Preul, M. C. (2017). Improving the utility of 1 H-MRS for the differentiation of glioma recurrence from radiation necrosis. Journal of neuro-oncology, 133(1), 97-105.

Devos, A., Lukas, L., Suykens, J., Vanhamme, L., Tate, A., Howe, F., . . Arus, C. (2004). Classification of brain tumours using short echo time 1H MR spectra. Journal of Magnetic Resonance, 170(1), 164-175.

Faria, A. V., Macedo Jr, F., Marsaioli, A., Ferreira, M., \& Cendes, F. (2011). Classification of brain tumor extracts by high resolution ${ }^{1} \mathrm{H}$ MRS using partial least squares discriminant analysis. Brazilian Journal of Medical and Biological Research, 44(2), 149164.

Fitzmaurice, C., Allen, C., Barber, R. M., Barregard, L., Bhutta, Z. A., Brenner, H., . . . Dandona, L. (2017). Global, regional, and national cancer incidence, mortality, years of life lost, years lived with disability, and disability-adjusted life-years for 32 cancer groups, 1990 to 2015: a systematic analysis for the global burden of disease study. JAMA oncology, 3(4), 524-548.

Georgiadis, P., Kostopoulos, S., Cavouras, D., Glotsos, D., Kalatzis, I., Sifaki, K., . . Nikiforidis, G. (2011). Quantitative combination of volumetric MR imaging and MR spectroscopy data for the discrimination of meningiomas from metastatic brain tumors by means of pattern recognition. Magnetic resonance imaging, 29(4), 525-535.

Graves, A., Mohamed, A.-r., \& Hinton, G. (2013). Speech recognition with deep recurrent neural networks. Paper presented at the 2013 IEEE international conference on acoustics, speech and signal processing.

Hekmatnia, A., Sabouri, M., Ghazavi, A. H., Far, P. S., Hekmatnia, F., Sofi, G. J., . . Salehi, M. (2019). Diagnostic value of Magnetic Resonance Spectroscopy (MRS) for detection of Brain Tumors in patients. Medical Science, 23(100), 939-945.

Hochreiter, S., \& Schmidhuber, J. (1997). Long short-term memory. Neural computation, 9(8), 1735-1780.

Hopfield, J. J. (1982). Neural networks and physical systems with emergent collective computational abilities. Proceedings of the national academy of sciences, 79(8), 2554-2558.

Horská, A., \& Barker, P. B. (2010). Imaging of brain tumors: MR spectroscopy and metabolic imaging. Neuroimaging Clinics, 20(3), 293-310.

Hourani, R., Brant, L., Rizk, T., Weingart, J. D., Barker, P. B., \& Horská, A. (2008). Can proton MR spectroscopic and perfusion imaging differentiate between neoplastic and nonneoplastic brain lesions in adults? American journal of neuroradiology, 29(2), 366-372.

Howe, F. A., \& Opstad, K. S. (2003). 1H MR spectroscopy of brain tumours and masses. NMR in Biomedicine: An International Journal Devoted to the Development and Application of Magnetic Resonance In Vivo, 16(3), 123-131.

INTERPRET. (2002). International network for pattern recognition of tumours using magnetic resonance. .

Kimura, T., Sako, K., Gotoh, T., Tanaka, K., \& Tanaka, T. (2001). In vivo single-voxel proton MR spectroscopy in brain lesions with ring-like enhancement. NMR in Biomedicine: An International Journal Devoted to the Development and Application of Magnetic Resonance In Vivo, 14(6), 339-349.

Ladd, M. E., Bachert, P., Meyerspeer, M., Moser, E., Nagel, A. M., Norris, D. G., . . Zaiss, M. (2018). Pros and cons of ultra-highfield MRI/MRS for human application. Progress in nuclear magnetic resonance spectroscopy, 109, 1-50.

Louis, D. N., Perry, A., Reifenberger, G., Von Deimling, A., Figarella-Branger, D., Cavenee, W. K., . . Ellison, D. W. (2016). The 2016 World Health Organization classification of tumors of the central nervous system: a summary. Acta neuropathologica, 131(6), 803-820.

Majos, C., Aguilera, C., Alonso, J., Julia-Sape, M., Castaner, S., Sanchez, J., . . . Arus, C. (2009). Proton MR spectroscopy improves discrimination between tumor and pseudotumoral lesion in solid brain masses. American journal of neuroradiology, 30(3), 544-551.

Majós, C., Alonso, J., Aguilera, C., Serrallonga, M., Pérez-Martín, J., Acebes, J. J., . . . Gili, J. (2003). Proton magnetic resonance spectroscopy (1 H MRS) of human brain tumours: assessment of differences between tumour types and its applicability in brain tumour categorization. European radiology, 13(3), 582-591.

McBride, D. Q., Miller, B. L., Nikas, D. L., Buchthal, S., Chang, L., Chiang, F., \& Booth, R. A. (1995). Analysis of brain tumors using 1H magnetic resonance spectroscopy. Surgical neurology, 44(2), 137-144.

Nachimuthu, D. S., \& Baladhandapani, A. (2014). Multidimensional texture characterization: on analysis for brain tumor tissues using MRS and MRI. Journal of digital imaging, 27(4), 496-506.

Nagori, M., \& Joshi, M. (2013). Methods and Algorithms for Extracting Values from MRS Graph for Brain Tumour Detection. IERI Procedia, 4, 331-336. 
Neugut, A. I., Sackstein, P., Hillyer, G. C., Jacobson, J. S., Bruce, J., Lassman, A. B., \& Stieg, P. A. (2019). Magnetic Resonance Imaging-Based Screening for Asymptomatic Brain Tumors: A Review. Oncologist, 24(3).

Ramin, S. L., Tognola, W. A., \& Spotti, A. R. (2003). Proton magnetic resonance spectroscopy: clinical applications in patients with brain lesions. Sao Paulo Medical Journal, 121(6), 254-259.

Schuster, M., \& Paliwal, K. K. (1997). Bidirectional Recurrent Neural Networks. IEEE transactions on Signal Processing, 45(11), 2673.

Soares, D., \& Law, M. (2009). Magnetic resonance spectroscopy of the brain: review of metabolites and clinical applications. Clinical radiology, 64(1), 12-21.

Tate, A. R., Underwood, J., Acosta, D. M., Julià-Sapé, M., Majós, C., Moreno-Torres, À., . . Murphy, M. M. (2006). Development of a decision support system for diagnosis and grading of brain tumours using in vivo magnetic resonance single voxel spectra. NMR in Biomedicine, 19(4), 411-434.

Tsolaki, E., Svolos, P., Kousi, E., Kapsalaki, E., Fountas, K., Theodorou, K., \& Tsougos, I. (2013). Automated differentiation of glioblastomas from intracranial metastases using 3T MR spectroscopic and perfusion data. International journal of computer assisted radiology and surgery, 8(5), 751-761.

Vicente, J., Fuster-Garcia, E., Tortajada, S., García-Gómez, J. M., Davies, N., Natarajan, K., . . . Monleón, D. (2013). Accurate classification of childhood brain tumours by in vivo 1H MRS-a multi-centre study. European Journal of Cancer, 49(3), 658667.

Vieira, B. H., Santos, A. C. d., \& Salmon, C. E. G. (2017). Pattern recognition of abscesses and brain tumors through MR spectroscopy: Comparison of experimental conditions and radiological findings. Research on Biomedical Engineering, 33(3), 185-194.

Weis, J., Ring, P., Olofsson, T., Ortiz-Nieto, F., \& Wikström, J. (2010). Short echo time MR spectroscopy of brain tumors: grading of cerebral gliomas by correlation analysis of normalized spectral amplitudes. Journal of Magnetic Resonance Imaging, 31(1), $39-45$.

WHO. (2018). Cancer. Retrieved from https://www.who.int/news-room/fact-sheets/detail/cancer

Wu, Y., Schuster, M., Chen, Z., Le, Q. V., Norouzi, M., Macherey, W., . . Macherey, K. (2016). Google's neural machine translation system: Bridging the gap between human and machine translation. arXiv preprint arXiv:1609.08144.

Zhang, X.-Y., Xie, G.-S., Liu, C.-L., \& Bengio, Y. (2016). End-to-end online writer identification with recurrent neural network. IEEE Transactions on Human-Machine Systems, 47(2), 285-292. 